\title{
Improvement of double-layer phosphor structure WLEDS in color homogeneity and luminous flux
}

\author{
Dieu An Nguyen Thi ${ }^{1}$, Phung Ton That ${ }^{2}$, Hoang Nam Nguyen ${ }^{3}$ \\ ${ }^{1}$ Faculty of Electrical Engineering Technology, Industrial University of Ho Chi Minh City, Vietnam \\ ${ }^{2}$ Faculty of Electronics Technology, Industrial University of Ho Chi Minh City, Vietnam \\ ${ }^{3}$ Modeling Evolutionary Algorithms Simulation and Artificial Intelligence, Faculty of Electrical and Electronics \\ Engineering, Ton Duc Thang University, Vietnam
}

\begin{abstract}
Article Info
Article history:

Received Feb 25, 2021

Revised May 20, 2021

Accepted Jul 10, 2021

\section{Keywords:}

Color homogeneity

Double-layer phosphor

Luminous flux

Monte Carlo theory

WLEDs

ABSTRACT

The concept of the analysis is to put a $\mathrm{CaAl}_{2} \mathrm{O}_{4}: \mathrm{Mn}^{2+}$ green phosphor layer on top of the YAG: $\mathrm{Ce}^{3+}$ yellow phosphor layer. After that, find the added $\mathrm{CaAl}_{2} \mathrm{O}_{4}: \mathrm{Mn}^{2+}$ concentration appropriate for the highest luminous flux (LF) and color homogeneity $(\mathrm{CH})$. In this analysis, five equivalent WLEDs were applied but with distinct color temperatures, including $5600 \mathrm{~K}-8500 \mathrm{~K}$. The findings showed that $\mathrm{CaAl}_{2} \mathrm{O}_{4}: \mathrm{Mn}^{2+}$ brings great benefits to increase not only the luminous flux but also the color homogeneity. Especially, the higher the $\mathrm{CaAl}_{2} \mathrm{O}_{4}: \mathrm{Mn}^{2+}$ concentration, the more the luminous flux released by WLEDs, owing to the risen content of the light of green in WLEDs. Nevertheless, as the $\mathrm{CaAl}_{2} \mathrm{O}_{4}: \mathrm{Mn}^{2+}$ concentration raised significantly, a small reduction in the color rendering metric (CRI) and color quality scale (CQS) occurred. This is supported by simulation and calculation according to the theory of Monte Carlo. The paper results are the crucial contribution to the manufacture of WLEDs with better optical performance and color homogeneity of remote phosphor configurations.
\end{abstract}

This is an open access article under the CC BY-SA license.

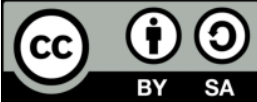

\section{Corresponding Author:}

Hoang Nam Nguyen

Modeling Evolutionary Algorithms Simulation and Artificial Intelligence

Faculty of Electrical and Electronics Engineering

Ton Duc Thang University

No. 19 Nguyen Huu Tho Street, Tan Phong Ward, District 7, Ho Chi Minh City, Vietnam

Email: nguyenhoangnam@tdtu.edu.vn

\section{INTRODUCTION}

The fourth potential illumination source generation used to replace the traditional one, phosphor transformed white light emitting diodes (pc-WLEDs), which has a wide range of prospects in lighting solutions, as can be shown in [1]-[5]. The implementation of white light emitting diodes has become increasingly popular in various areas of everyday routine of people, such as landscape, street lighting, backlighting, while the efficiency of illumination harness and the consistency of angles of the associated chromatic temperature of the white LEDs are still the demanding factors that limit its enhancement [6]-[8]. Future advancements in luminescent performance and color consistency are critical, given the steady growth in consumer demand and implementations [9], [10]. A combination of the light of blue from the reverse red phosphorus with the light of yellow from the LED chip is the most common method for producing white light today. While this idea seems to be very common, it cannot be denied that the layout of LEDs and the layout of phosphorous layers, especially the color rendering index, play a significant role in assessing the luminous quality [11]-[14]. Several common methods of phosphorus coating have been suggested in order to manufacture LEDs, such as dispensing and conformal coatings [15]-[18]. Still, these configurations do not 
have good lighting chromaticity due to the deterioration of the illuminating transformation of phosphorus matter caused by the yellow emitted phosphorus directly contacting the LED chips, leads to a temperature rise at the juncture of the LED and phosphorus layers. Minimizing the influence of heat will therefore increase the phosphor's efficiency and keep the phosphorus from being irremediably harmed. A lot of earlier experiments have shown that the heating effect is reduced with the remote structure of phosphor layers that are located distant from the heat origin (LED chip). With an adequate space set between the phosphor compounding and the LED chip, the backscatter and dissemination of inner lighting could be restricted. This approach is the optimal solution for LED heat control, so the luminous efficiency and color consistency of LEDs can be increased [19], [20]. The distant phosphor configuration, on the other hand, is adequately suited for regular illumination but does not meet other demands for many other lighting implementations, which is perhaps why developing the upcoming generation of LEDs is critical. Several new remote phosphorus structures were proposed for future developments, with the goal of minimizing phosphorus backscatter to the chip and improving luminescent efficiency. Some other research found that a reversed cone lens encapsulant and a distant phosphorus layer covering the ring would redirect light beams from the blue chip to the LED surface, decreasing internal reflection losses within the LED [21]. A patterned distant phosphorus configuration with a clear area in the perimeter zone and no coating phosphorus on the outer surface could achieve optimum dependence of angles associated color temperature homogeneity and chromatic stabilization [22]. In contrast, the patterned sapphire substrate applied to the remote phosphorus in a far-field pattern could have even greater homogeneity of the associated color temperature than a standard template [23], [24]. To enhance the illumination performance of LEDs, distant phosphorus with a double-layer packet is suggested. The above-mentioned researches did concentrate on enhancing the uniformity of color and luminous flux performance of phosphorus remote structure WLEDs, yet investigated primarily on single-chip WLEDs and models with low color temperature. In the meantime, it is difficult to develop the optical parameters for high color temperature WLEDs.

This article suggests a remote phosphorous double-layer layout to increase the color standard of WLEDs with varying color temperatures from $5600 \mathrm{~K}$ to $8500 \mathrm{~K}$. The novel concept of the article is to utilize the $\mathrm{CaAl}_{2} \mathrm{O}_{4}: \mathrm{Mn}^{2+}$ green phosphor layer to raise the composition of green light in WLEDs, leading to better luminous flux (LF) and color homogeneity $(\mathrm{CH})$. The article reports in detail the combination of chemical elements of $\mathrm{CaAl}_{2} \mathrm{O}_{4}: \mathrm{Mn}^{2+}$ affecting the visual properties of WLEDs as well. The results of the article show that $\mathrm{LF}$ and $\mathrm{CH}$ significantly improve with the addition of phosphor layers $\mathrm{CaAl}_{2} \mathrm{O}_{4}: \mathrm{Mn}^{2+}$. However, to prevent a deep fall in the color rendering ability (CRI) and color quality ratio (CQS) when the green phosphorus concentration rises extremely, the adequate $\mathrm{CaAl}_{2} \mathrm{O}_{4}: \mathrm{Mn}^{2+}$ concentration should be determined. Three notable points can be reported with the additional layer of green phosphor on top of the layer of yellow phosphor YAG:Ce ${ }^{3+}$ are: the increased green light component leading to heightened the spectrum of white light emitting light, better emitted flux, and higher dispersion and transmittance of WLED illumination with the risen $\mathrm{CaAl}_{2} \mathrm{O}_{4}: \mathrm{Mn}^{2+}$ concentration. The selection of proper concentration of $\mathrm{CaAl}_{2} \mathrm{O}_{4}: \mathrm{Mn}^{2+}$ is therefore essential for the WLEDs' balance of illuminating beam and color quality.

\section{COMPUTATIONAL SIMULATION}

\subsection{Provision of green-emitting $\mathrm{CaAl}_{2} \mathrm{O}_{4}: \mathrm{Mn}^{2+}$ phosphor}

$\mathrm{CaAl}_{2} \mathrm{O}_{4}: \mathrm{Mn}^{2+}$ particles are forms of yellow-green phosphorus and become more popular owing to their peak emission of $2.28 \mathrm{eV}$ and a lot of excellent features such as optimal quantum yield and high temperature permanence. The particle sizes and concentration of $\mathrm{CaAl}_{2} \mathrm{O}_{4}: \mathrm{Mn}^{2+}$ phosphors may have a significant impact on their illumination characteristics. The ingredients consist of $\mathrm{CaCO}_{3}, \mathrm{Al}_{2} \mathrm{O}_{3}, \mathrm{MnCO}_{3}, \mathrm{CaF}_{2}$ and $\mathrm{Mn}^{2+}$ ion, all of which, as seen in Table 1, are used as raw materials. In addition, $\mathrm{CaAl}_{2} \mathrm{O}_{4}: \mathrm{Mn}^{2+}$ is used especially for fluorescent lamps with very high-loading and a long lifetime. As a result, it is amongst the most popular phosphors of commercially produced oxide. Overall, the $\mathrm{CaAl}_{2} \mathrm{O} 4: \mathrm{Mn}^{2+}$ manufacturing phase is being as: First of all, to be combined together, we slurry all the ingredients in the water. They are then ball-milled into small particles in the water. After that, when they are dried in the air, the materials will be powdered. Next, this powder will be fired with $\mathrm{CO}$ at $1300^{\circ} \mathrm{C}$ within an hour in covered alumina crucibles and powderized by dry milling. Then, with $\mathrm{CO}$ at $1200^{\circ} \mathrm{C}$ within an hour, they are fired again in open quartz boats. Eventually, we wash the product in a liter of water in a solution of $\mathrm{NH}_{4} \mathrm{Cl}$ and then several times in plain water.

Table 1. Combination of chemical elements of green-emitting phosphor $\mathrm{CaAl}_{2} \mathrm{O}_{4}: \mathrm{Mn}^{2+}$

\begin{tabular}{ccc}
\hline Ingredient & Mole \% & By weight $(\mathrm{g})$ \\
\hline $\mathrm{CaCO}_{3}$ & 93 & 93 \\
$\mathrm{Al}_{2} \mathrm{O}_{3}$ & 200 (of $\mathrm{Al})$ & 102 \\
$\mathrm{MnCO}_{3}$ & 2 & 2.3 \\
$\mathrm{CaF}_{2}$ & 5 & 3.9 \\
\hline
\end{tabular}

Bulletin of Electr Eng \& Inf, Vol. 10, No. 5, October 2021 : 2513 - 2519 


\subsection{Simulation of MC-WLEDs}

The layers of phosphors in actual MCW-LEDs are modeled with clear silicone sheets utilizing the simulating software of LightTools 9.0. This simulation procedure is carried out over two distinct time periods; (1) it is critical to identify and construct the configuration models and optic features of MCW-LEDs; (2) the optic impacts of phosphor layers are then well regulated by the $\mathrm{CaAl}_{2} \mathrm{O}_{4}: \mathrm{Mn}^{2+}$ concentration variation. To evaluate the effect of $\mathrm{YAG}: \mathrm{Ce}^{3+}$ and $\mathrm{CaAl}_{2} \mathrm{O}_{4}: \mathrm{Mn}^{2+}$ phosphor compounding on the performance of MCW-LED lamps, some comparisons must be made. Particularly, effects of the green-yellow dual-layer remote phosphorus model, with mean CCTs of $5600 \mathrm{~K}-8500 \mathrm{~K}$, are stated and explained. Figure 1 (a), (b), (c), (d) depicts a detailed overview of a MCW-LED lamp with conformal phosphor compounding and a mean CCT of $8500 \mathrm{~K}$. Apart from the green phosphor $\mathrm{CaAl}_{2} \mathrm{O}_{4}: \mathrm{Mn}^{2+}$, the specifications of other WLED elements are also expressed. The reflector's base length is $8 \mathrm{~mm}$, its height is $2.07 \mathrm{~mm}$, and its top surface length is $9.85 \mathrm{~mm}$. The conformal phosphor compounding coats nine chips with a thickness of $0.08 \mathrm{~mm}$. Each LED chip is attached to the reflector space through a squared ground region of $1.14 \mathrm{~mm} 2$ and $0.15-\mathrm{mm}$ height. The reflective radiation of a blue LED chip is $1.16 \mathrm{~W}$, with a wavelength that peaks at $453 \mathrm{~nm}$.

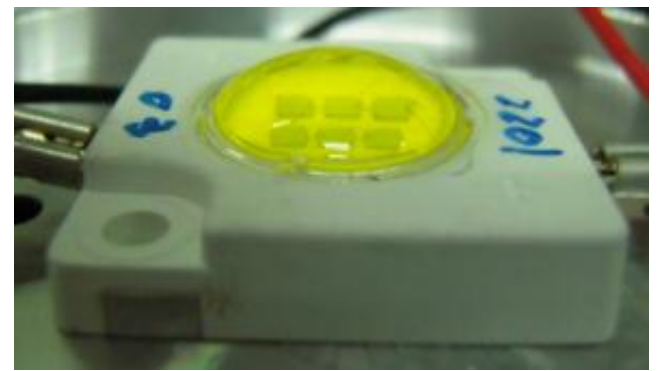

(a)

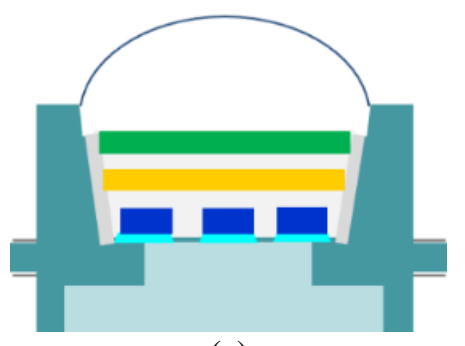

(c)

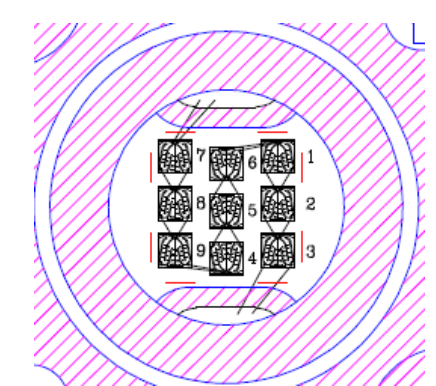

(b)

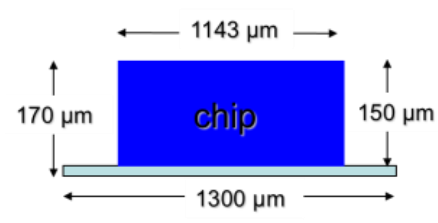

(d)

Figure 1. Schematic diagrams of WLEDs; (a) real WLEDs, (b) bonding diagram, (c) double-layer phosphor model illustration, (d) side view of blue chip

\section{RESULTS AND ANALYSIS}

The reverse mutation among the concentration of green $\mathrm{CaAl}_{2} \mathrm{O}_{4}: \mathrm{Mn}^{2+}$ and yellow YAG:Ce ${ }^{3+}$ films can be seen in Figure 2. There are two meanings of this change: one is to preserve mean CCTs, the other is to impact the absorption and scattering in WLEDs of two phosphor layers. The color quality and the performance of luminous flux of WLEDs are ultimately influenced by this. Thus, the selection of $\mathrm{CaAl}_{2} \mathrm{O}_{4}: \mathrm{Mn}^{2+}$ concentration defines the color standard of WLEDs. Whenever the $\mathrm{CaAl}_{2} \mathrm{O}_{4}: \mathrm{Mn}^{2+}$ goes from $2 \%$ wt. to $20 \%$ wt., the concentration of yellow YAG:Ce ${ }^{3+}$ declines to preserve the mean CCTs. There is a similarity with WLEDs with varying CCTs in the range of $5600 \mathrm{~K}-8500 \mathrm{~K}$.

Figures 3-7 show the influence of changing concentration of $\mathrm{CaAl}_{2} \mathrm{O}_{4}: \mathrm{Mn}^{2+}$ green phosphor on the transmittance range of WLEDs. It is possible to make a decision based on the manufacturer's specifications. WLEDs that need high color performance can minimize illuminated beam by a minor fraction. White light is the combination of the spectral field displayed in Figures 3-7. The five figures depict spectra at $5600 \mathrm{~K}$, $6600 \mathrm{~K}, 7000 \mathrm{~K}, 7700 \mathrm{~K}$, and $8500 \mathrm{~K}$. Clearly, the intensity trend increases with concentration in two regions of the lighting spectral range: $420 \mathrm{~nm}-480 \mathrm{~nm}$ and $500 \mathrm{~nm}-640 \mathrm{~nm}$. This increase in the two-band emission spectra demonstrates an increase in the output luminous flux. Moreover, the blue-light scattering in WLED is increased, which means the scattering in the phosphorous layer and in WLEDs is increased, resulting in color uniformity becoming favored. This is a significant finding when $\mathrm{CaAl}_{2} \mathrm{O}_{4}: \mathrm{Mn}^{2+}$ is used. Controlling the color uniformity of the high temperature remote phosphor structure, in particular, is hard. This study concluded 
that $\mathrm{CaAl}_{2} \mathrm{O}_{4}: \mathrm{Mn}^{2+}$, at both low and high CCTs $(5600 \mathrm{~K}$ and $8500 \mathrm{~K})$, will improve the color quality of WLEDs.

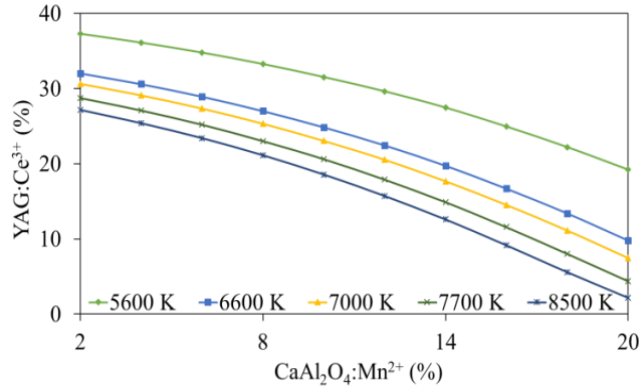

Figure 2. Changing the concentration of phosphor to preserve the average CCT

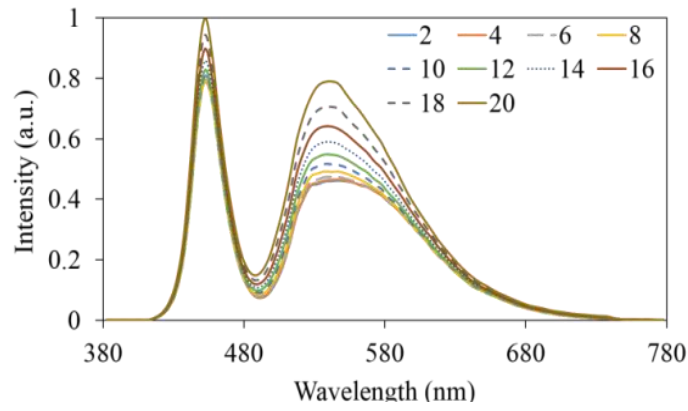

Figure 4. Spectrum of $6600 \mathrm{~K}$ WLEDs with $\mathrm{CaAl}_{2} \mathrm{O}_{4}: \mathrm{Mn}^{2+}$ wt

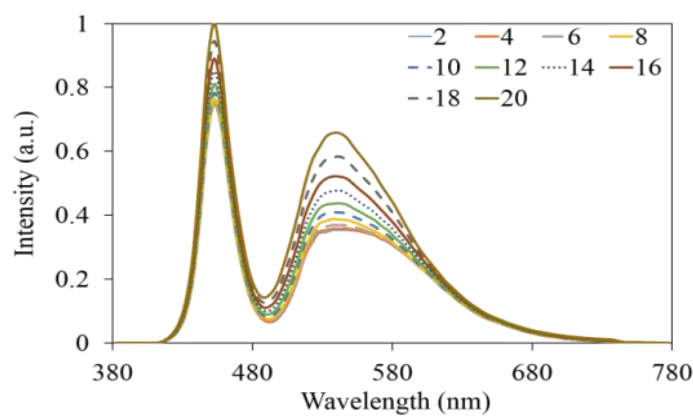

Figure 6. Spectrum of $7700 \mathrm{~K}$ WLEDs with $\mathrm{CaAl}_{2} \mathrm{O}_{4}: \mathrm{Mn}^{2+}$ wt

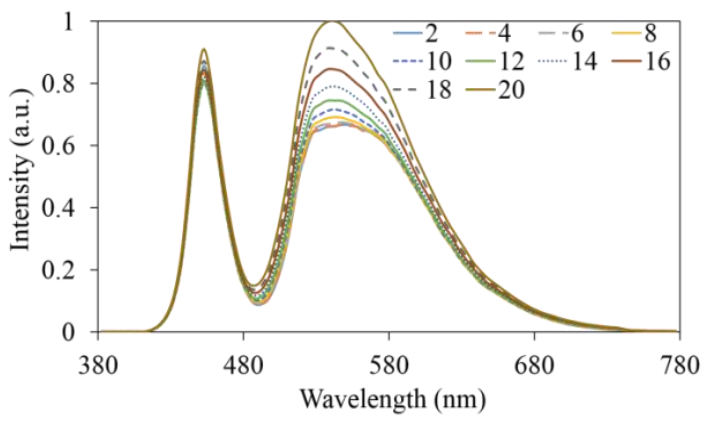

Figure 3. Spectrum of $5600 \mathrm{~K}$ WLEDs with $\mathrm{CaAl}_{2} \mathrm{O}_{4}: \mathrm{Mn}^{2+}$ wt

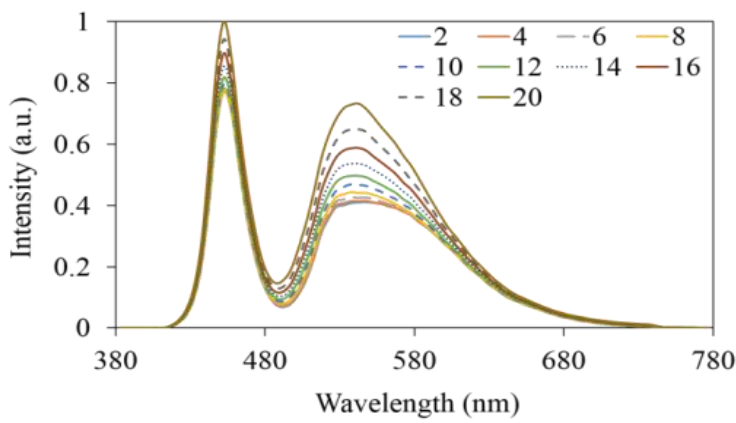

Figure 5. Spectrum of $7000 \mathrm{~K}$ WLEDs with $\mathrm{CaAl}_{2} \mathrm{O}_{4}: \mathrm{Mn}^{2+} \mathrm{wt}$

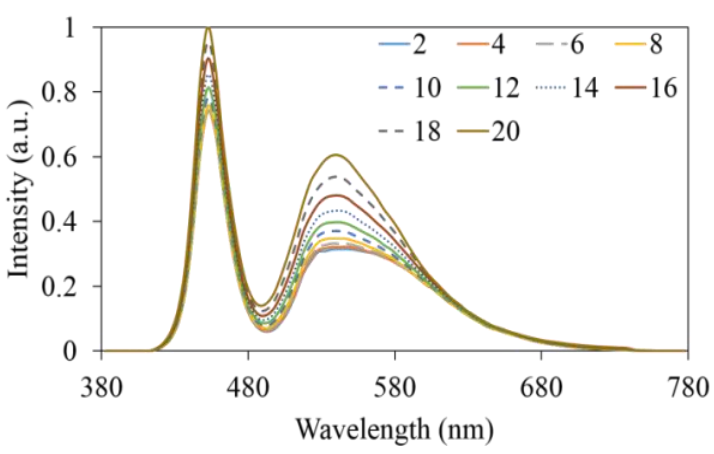

Figure 7. Spectrum of $8500 \mathrm{~K}$ WLEDs with $\mathrm{CaAl}_{2} \mathrm{O}_{4}: \mathrm{Mn}^{2+} \mathrm{wt}$

This section will illustrate and show the statistical structure of transferred blue lighting and transformed yellow lighting in the dual-layer phosphorus structure, which can result in a significant improvement in LED performance [25], [26]. For a single-layer distant phosphorus packet with the thickness of phosphorus layer set at $2 h$, the transferred blue lighting and transformed yellow lighting are as shown in (1) and (2):

$$
P B_{1}=P B_{0} \times e^{-2 \alpha_{B 1} h}
$$




$$
P Y_{1}=\frac{1}{2} \frac{\beta_{1} \times P B_{0}}{\alpha_{B 1}-\alpha_{Y 1}}\left(e^{-2 \alpha_{Y 1} h}-e^{-2 \alpha_{B 1} h}\right)
$$

For the double-layer distant phosphor packet, the transferred light of blue and the transformed light of yellow, with $h$ is the phosphor-layer thickness, are defined as (3), (4):

$$
\begin{aligned}
& P B_{2}=P B_{0} \times e^{-2 \alpha_{B 2} h} \\
& P Y_{2}=\frac{1}{2} \frac{\beta_{2} \times P B_{0}}{\alpha_{B 2}-\alpha_{Y 2}}\left(e^{-2 \alpha_{Y 2} h}-e^{-2 \alpha_{B 2} h}\right)
\end{aligned}
$$

Where $h$ indicates each phosphor-layer thickness. To define the one- and two-layered distant phosphor packages, the " 1 " and " 2 " subscriptions are used. $\beta$ indicates the transfer factor for the light of blue transforming to the light of yellow. $\gamma$ is the backscatter factor of yellow light. The lighting intensity of the blue LED shown by $P B_{0}$ is the blue-lighting intensity $(P B)$ and the yellow-lighting intensity $(P Y) . \alpha_{B}$ and $\alpha_{Y}$ explain the sections of the losing energy of the blue and yellow beams through their spreading of the phosphorus layer respectively. As compared to a single-layer configuration, the illumination performance of pc-LEDs with a dual-layer phosphorous configuration is significantly higher:

$$
\frac{\left(P B_{2}+P Y_{2}\right)-\left(P B_{1}+P Y_{1}\right)}{P B_{1}+P Y_{1}}>0
$$

In (5) shows that dual-layer distant phosphorus WLEDs have a higher luminescent quality than single-layer phosphorus WLEDs. Thus, the paper demonstrated the efficacy of the released illuminating beam of the green-yellow double-layer distant phosphor model. The findings in Figure 8 demonstrate that the illuminating beam released increases considerably as the $\mathrm{CaAl}_{2} \mathrm{O}_{4}: \mathrm{Mn}^{2+}$ concentration increases from $2 \%$ wt. to $20 \%$ wt. The color variance is greatly decreased with the phosphor $\mathrm{CaAl}_{2} \mathrm{O}_{4}: \mathrm{Mn}^{2+}$ concentration in all three average CCTs, according to the findings of Figure 9. These achievements should be attributed to the green phosphor film's absorption feature. As the $\mathrm{CaAl}_{2} \mathrm{O}_{4}: \mathrm{Mn}^{2+}$ phosphor absorbs the light of blue from the LED chip; these green phosphor particles convert it to the light of green. The $\mathrm{CaAl}_{2} \mathrm{O}_{4}: \mathrm{Mn}^{2+}$ particles absorb yellow lighting in addition to the blue lighting from the chip. However, the absorption properties of the substrate contribute to getting stronger blue light absorption, compared to the other absorption event. As a result of the inclusion of $\mathrm{CaAl}_{2} \mathrm{O}_{4}: \mathrm{Mn}^{2+}$, the green light content in WLEDs increases, resulting in an improvement in the color uniformity indicator. Color homogeneity is a vital parameter of modern WLED lamp parameters. Undoubtedly, the better the color homogeneity coefficient, the more expensive WLED white light. The benefit of using $\mathrm{CaAl}_{2} \mathrm{O}_{4}: \mathrm{Mn}^{2+}$ is its least expensive application. $\mathrm{CaAl}_{2} \mathrm{O}_{4}: \mathrm{Mn}^{2+}$ can therefore be commonly used.

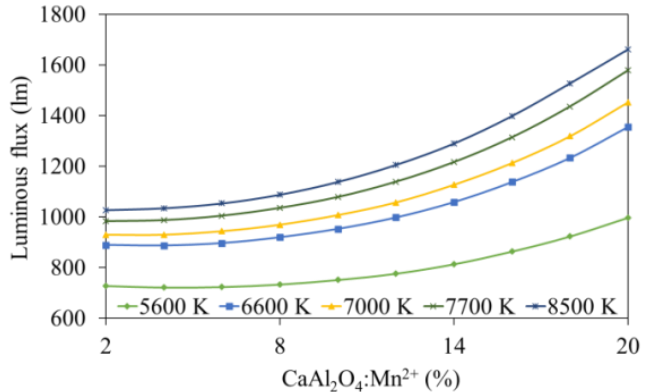

Figure 8. Luminous flux of WLEDs with $\mathrm{CaAl}_{2} \mathrm{O}_{4}: \mathrm{Mn}^{2+}$ wt

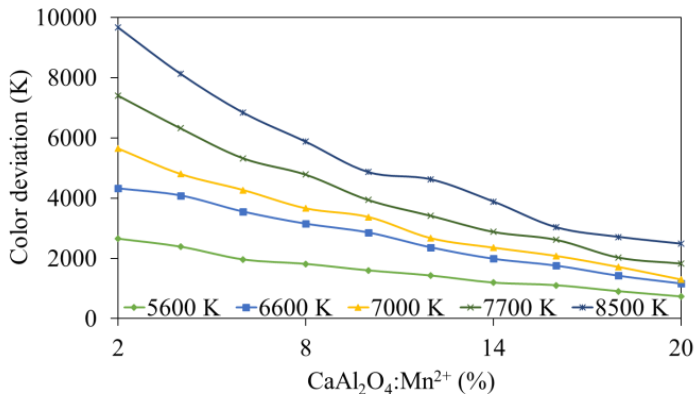

Figure 9. Color deviation of WLEDs with $\mathrm{CaAl}_{2} \mathrm{O}_{4}: \mathrm{Mn}^{2+}$ wt

Color conformity is one of the notable factors to consider when assessing the color consistency of WLEDs. Yet, color consistency cannot be said to be decent with a high color homogeneity index. Therefore, recent studies provided an index for color rendering and a scale for color quality. When the color rendering 
indicator is illuminated by an illumination, it assesses the real color of a thing. The unbalance of color is caused by the excessive amount of green light among the three major colors: blue, yellow and green. This influences the chromatic standard of WLEDs, leading to the decline of color fidelity of a WLED. With the use of $\mathrm{CaAl}_{2} \mathrm{O}_{4}: \mathrm{Mn}^{2+}$ remote phosphor layer, the findings in Figure 10 indicate a slight reduction in CRI. Nonetheless, these are appropriate because CRI is merely a shortcoming in CQS. When drawing a comparison between CRI and CQS, CQS is more significant and more difficult to accomplish. CQS is a three-factor indicator that is calculated by three factors: the color rendering index, the viewer's selection, and color coordinate. For these three important variables, CQS is almost a real total indicator of color consistency. Figure 11 depicts the enhancement of CQS in the existence of the distant phosphor $\mathrm{CaAl}_{2} \mathrm{O}_{4}: \mathrm{Mn}^{2+}$ layer. Moreover, as the concentration of $\mathrm{CaAl}_{2} \mathrm{O}_{4}: \mathrm{Mn}^{2+}$ is increased, CQS does not change significantly if the concentration of $\mathrm{CaAl}_{2} \mathrm{O}_{4}: \mathrm{Mn}^{2+}$ is less than $10 \%$ wt. When the $\mathrm{CaAl}_{2} \mathrm{O}_{4}: \mathrm{Mn}^{2+}$ concentration is higher than $10 \%$ wt., both CRI and CQS are greatly decreased due to extreme color loss when green is predominant. As a consequence, when using green phosphor $\mathrm{CaAl}_{2} \mathrm{O}_{4}: \mathrm{Mn}^{2+}$, proper concentration selection is critical.

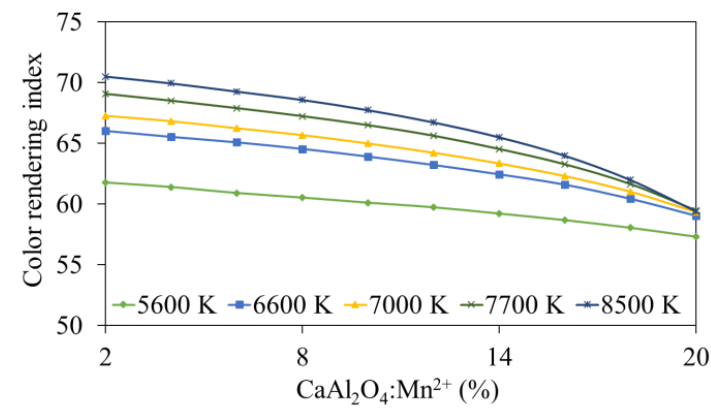

Figure 10. Color rendering index of WLEDs with $\mathrm{CaAl}_{2} \mathrm{O}_{4}: \mathrm{Mn}^{2+}$ wt

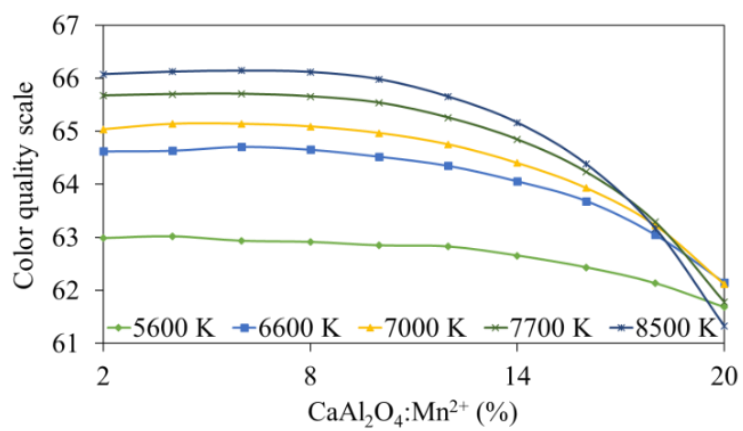

Figure 11. Color quality scale of WLEDs with $\mathrm{CaAl}_{2} \mathrm{O}_{4}: \mathrm{Mn}^{2+}$ wt

\section{CONCLUSION}

The paper represents the influence of $\mathrm{CaAl}_{2} \mathrm{O}_{4}: \mathrm{Mn}^{2+}$ green phosphorus on the optic characteristics of the configuration of double-layer phosphorus. The research showed that $\mathrm{CaAl}_{2} \mathrm{O}_{4}: \mathrm{Mn}^{2+}$ is a suitable choice for improving color uniformity using Monte Carlo computational simulations. Furthermore, this green phosphor is applicable not only to WLEDs with low color temperatures, for example $5600 \mathrm{~K}$, but also to those with a color temperature greater than $7700 \mathrm{~K}$, such as $8500 \mathrm{~K}$ in our study. The findings of this analysis have thus accomplished the objective of enhancing the standard of color and luminous flux, which is very complicated with the remote configuration of phosphorus. However, one minor disadvantage occurs for CRI and CQS. When the concentration of $\mathrm{CaAl}_{2} \mathrm{O}_{4}: \mathrm{Mn}^{2+}$ is increased excessively, either CRI or CQS decrease significantly. It is therefore necessary to select the proper concentration, based on the objectives of the manufacturer. In relation to producing greater color uniformity and luminous flux WLEDs, the paper has given a great amount of essential information for reference.

\section{REFERENCES}

[1] X. Li, D. Kundaliya, Z. J. Tan, M. Anc, and N. Fangg, "Projection lithography patterned high-resolution quantum dots/thiol-ene photo-polymer pixels for color down conversion," Optics express, vol. 27, pp. 30864-30874, 2019, doi: 10.1364/oe.27.030864.

[2] P. Kumar and N. Nishchal, "Enhanced exclusive-OR and quick response code-based image encryption through incoherent illumination," Applied Optics, vol. 58, pp. 1408-1412, 2019, doi: 10.1364/AO.58.001408.

[3] V. Dumont, S. Bernard, C. Reinhardt, A. Kato, M. Ruf, and J. C. Sankey, "Flexure-tuned membrane-at-the-edge optomechanical system," Optics express, vol. 27, no. 18, pp. 25731-25748, 2019, doi: 10.1364/OE.27.025731.

[4] S. Keshri, et al., "Stacked volume holographic gratings for extending the operational wavelength range in LED and solar applications," Applied Optic, vol. 59, no. 8, pp. 2569-2579, 2020, doi: 10.1364/AO.383577.

[5] Ferrero, J. L. Velazquez, A. Pons, and J. Campos "Index for the evaluation of the general photometric performance of photometers," Optics express, vol. 26, no. 14, pp. 18633-18643, 2018, doi: 10.1364/OE.26.018633.

[6] T. Hu, et al., "Demonstration of color display metasurfaces via immersion lithography on a 12-inch silicon wafer," Optics express, vol. 26, no. 15, pp. 19548-19554, 2018, doi: 10.1364/OE.26.019548. 
[7] X. Huang, J. Liang, B. Li, L. Sun, and J. Lin, "High-efficiency and thermally stable far-red-emitting $\mathrm{NaLaMgWO}_{6}: \mathrm{Mn}^{4+}$ phosphorsfor indoor plant growth light-emitting diodes," Optics Letters, vol. 43, no. 14, pp. 3305-3308, 2018, doi: 10.1364/OL.43.003305.

[8] Y. Peng, et al., "Flexible fabrication of a patterned red phosphor layer on a YAG:Ce ${ }^{3+}$ phosphor-in-glass for highpower WLEDs," Optical Materials Express, vol. 8, no. 3, pp. 605-614, 2018, doi: 10.1364/OME.8.000605.

[9] Zhang, et al., "Exciton photoluminescence of $\mathrm{CsPbBr}_{3} @ \mathrm{SiO}_{2}$ quantum dots and its application as a phosphor material in light-emitting devices," Optical Materials Express, vol. 10, no. 4, pp. 1007-1017, 2020, doi: 10.1364/OME.389847.

[10] H. Liu, Y. Shi, and T. Wang, "Design of a six-gas NDIR gas sensor using an integrated optical gas chamber," Optics Express, vol. 28, no. 8, pp. 11451-11462, 2020, doi: 10.1364/OE.388713.

[11] A. Keller, P. Bialecki, T. J. Wilhelm, and M. K. Vetter, "Diffuse reflectance spectroscopy of human liver tumor specimens - towards a tissue differentiating optical biopsy needle using light emitting diodes," Biomedical Optics Express, vol. 9, no. 3, pp. 1069-1081, 2018, doi: 10.1364/BOE.9.001069.

[12] Y. Wang, Y. Liu, J. Shen, X. Wang, and X. Yan, "Controlling optical temperature behaviors of $\mathrm{Er}^{3+} \mathrm{doped}^{3}$ $\mathrm{Sr}_{2} \mathrm{CaWO}_{6}$ through doping and changing excitation powers," Optical Materials Express, vol. 8, no. 7, pp. 19261939, 2018, doi: 10.1364/OME.8.001926.

[13] K. Werfli et al., "Experimental Demonstration of High-Speed $4 \times 4$ Imaging Multi-CAP MIMO Visible Light Communications," in Journal of Lightwave Technology, vol. 36, no. 10, pp. 1944-1951, 15 May15, 2018, doi: 10.1109/JLT.2018.2796503.

[14] Z. Wen, et al., "Fabrication and optical properties of Pr3+-doped Ba, Sn, Zr, Mg, Ta. O3 transparent ceramic phosphor," Optics Letters, vol. 43, no. 11, pp. 2438-2441, 2018, doi: 10.1364/OL.43.002438.

[15] H. Kim, Y.-Jun Seo, and Y. Kwak, "Transparent effect on the gray scale perception of a transparent OLED display," Optics Express, vol. 26, no. 4, pp. 4075-4084, 2018, doi: 10.1364/OE.26.004075.

[16] H. P. Huang, M. Wei, and L.-Chen Ou, "White appearance of a tablet display under different ambient lighting conditions," Optics Express, vol. 26, no. 4, pp. 5018-5030, 2018, doi: 10.1364/OE.26.005018.

[17] J. Henning, J. Williamson, H. Martin, and X. Jiang, "Improvements to dispersed reference interferometry: beyond the linear approximation," Applied Optics, vol. 58, no. 1, pp. 131-136, 2019, doi: 10.1364/AO.58.000131.

[18] R. Deeb, J. V. de Weijer, D. Muselet, M. Hebert, and A. Tremeau, "Deep spectral reflectance and illuminant estimation from self-interreflections," Journal of the Optical Society of America A, vol. 36, no. 1, pp. 105-114, 2019, doi: 10.1364/JOSAA.36.000105.

[19] M. Dupont-Nivet, I. Westbrook, and S. Schwartz, "The role of trap symmetry in an atom-chip interferometer above the Bose-Einstein condensation threshold," in 2019 Conference on Lasers and Electro-Optics Europe and European Quantum Electronics Conference, OSA Technical Digest, Optical Society of America, 2019., paper jsv_1_3.

[20] W. Wang and L. Cai, "On the development of an effective image acquisition system for diamond quality grading," Applied Optics, vol. 57, no. 33, pp. 9887-9897, 2018, doi: 10.1364/AO.57.009887.

[21] P. Zhu, H. Zhu, S. Thapa, and G. C. Adhikari, "Design rules for white light emitters with high light extraction efficiency," Optics Express, vol. 27, no. 16, pp. A1297-A1307, 2019, doi: 10.1364/OE.27.0A1297.

[22] H. Yuce, T. Guner, S. Balci, and M. M. Demir, "Phosphor-based white LED by various glassy particles: control over luminous efficiency," Optics Letters, vol. 44, no. 3, pp. 479-482, 2019, doi: 10.1364/OL.44.000479.

[23] X. Sun, D. Zou, Z. Qu, and I. B. Djordjevic, "Run-time reconfigurable adaptive LDPC coding for optical channels," Optics Express, vol. 26, no. 22, pp. 29319-29329, 2018, doi: 10.1364/OE.26.029319.

[24] N. T. Canh, T. T. T. Can, and W.-S. Choi, "Electrohydrodynamic jet-sprayed quantum dots for solution-processed light-emitting-diodes," Optical Materials Express, vol. 8, no. 12, pp. 3738-3747, 2018, doi: 10.1364/OME.8.003738.

[25] M.Kandel, W. Lu, J. Liang, O. Aydin, T. A. Saif, and G. Popescu, "Cell-to-cell influence on growth in large populations," Biomedical Optics Express, vol. 10, no. 9, pp. 4664-4675, 2019, doi: 10.1364/BOE.10.004664.

[26] J. Wang, Y. Zhou, and Y. Yang, "Rapid 3D measurement technique for colorful objects employing RGB color light projection," Applied Optics, vol. 59, no. 7, pp. 1907-1915, 2020, doi: 10.1364/AO.382302. 